\title{
Catalytic transformation of ethanol into 1,3-butadiene
}

\author{
Matthew D Jones
}

\begin{abstract}
1,3-Butadiene is an important constituent of many products that we rely upon. It is currently prepared from non-sustainably derived sources. However, in the early part of the $20^{\text {th }}$ Century the use of ethanol as a source of 1,3-butadiene has been reported. With the arrival of a cheap and bountiful supply of crude-oil derived sources the need for the sustainable route was deemed unnecessary. In recent years the conversion of ethanol to 1,3-butadiene has undergone somewhat of a mini resurgence as the chemical industry looks to try to find a sustainable and secure route to this important building block. This review will emphasise some of the most recent work in the field and look ahead to what needs to be achieved to make this research a reality.
\end{abstract}

Keywords: Ethanol, 1,3-butadiene, Heterogeneous, Catalysis

\section{Introduction}

1,3-Butadiene (1,3-BD) is an important building block in many chemical processes. Its main use is as a monomer for the production of synthetic rubbers [1]. The most significant use of $1,3-\mathrm{BD}$ is in the manufacturing of styrenebutadiene (SBR) rubbers which are primarily used in the production of tyres. Currently, 1,3-BD is mainly formed as a by-product of the naphtha steam cracking process - a coproduct of ethene manufacturing - with 1,3-BD being isolated after costly extractive distillation steps. 1,3-BD can also be produced by the dehydrogenation of butane or butene (Houdry process) [1,2]. In recent years the cost of $1,3-\mathrm{BD}$ has fluctuated massively and the price has increased, for example the cost of a tonne of 1,3-BD was ca. \$1,500 USD in March 2014 compared to \$850 USD in August 2013. The cost (and fluctuation) is not sustainable in the long term for the major users of this important building block. The increase in cost can be attributed to several factors i) the increasing rise in the price of crude oil; ii) the move to lighter feedstocks from the cracking process and iii) the "shale-gas" surge in Europe and the US [3]. Shale gas contains ethane which can be dehydrogenated to ethene - which is a 1,3-BD free route and consequently causing a reduction in ethene production from the steam cracking route and, hence,

Correspondence: mj205@bath.ac.uk

Department of Chemistry, University of Bath, Claverton Down, Bath BA2 7AY, UK 


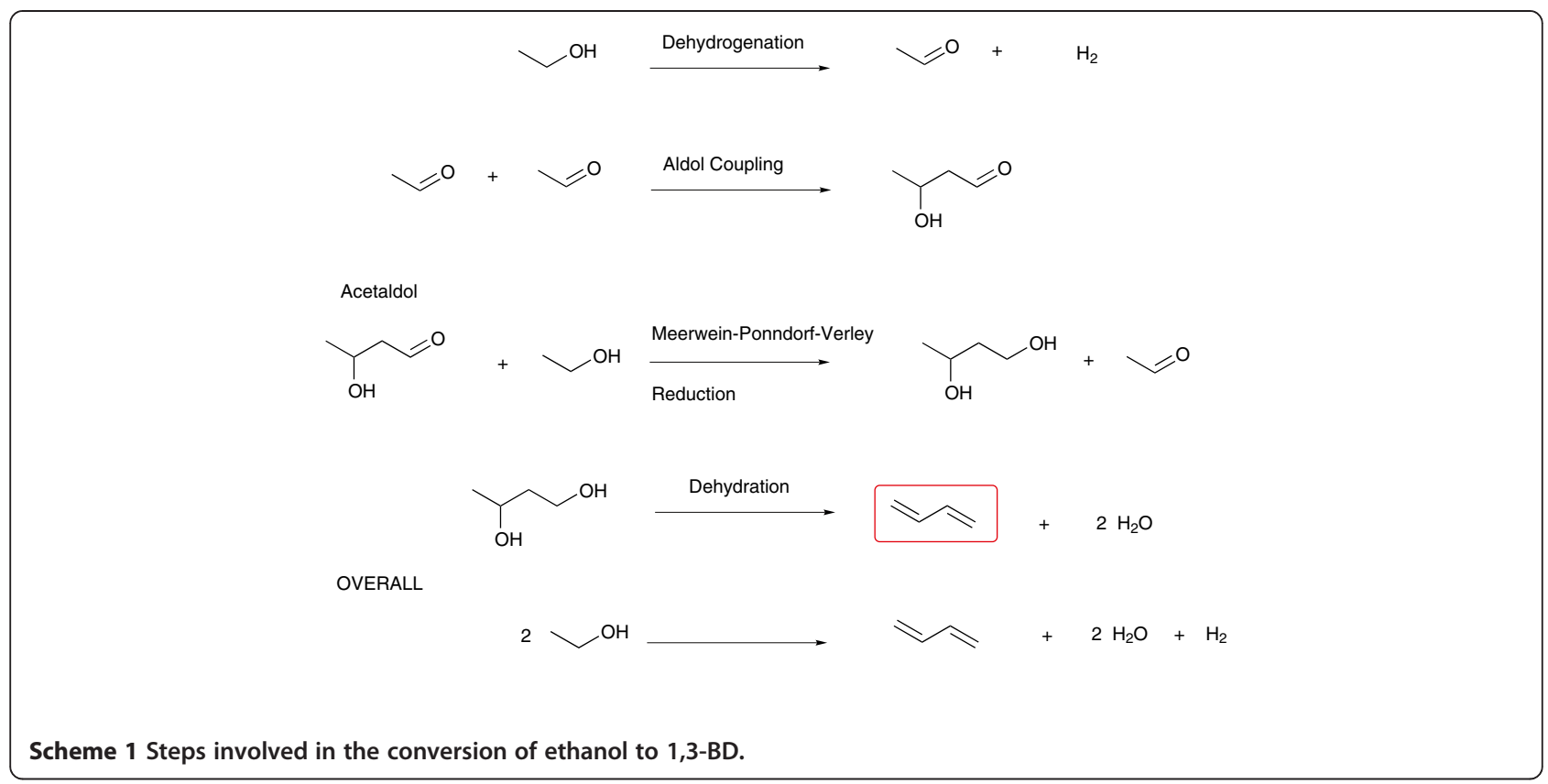

ethane/ethene. Acetaldehyde can also be thought of as a by-product, but this can be recycled into the feed and reused. The financial viability of the process will depend upon minimising the formation of by-products and thus maximising the overall process yield of 1,3-BD.

The success of this technology will depend on a cheap and readily available source of ethanol [4]. As with all processes relying on sustainable and renewable resources the new route must not impart undesired consequences on existing supply chains or impact on food provisions and security. With the arrival of algal biomass for bioethanol production then the possible environmental concerns can be circumvented [5]. The sustainable assessment (techno-economic) of the ethanol to 1,3-BD process has also been investigated by Patel and co-workers, who found that the bio-based route compares favourably with the traditional naphtha-based route [6,7].

\section{Review}

The conversion of ethanol to 1,3-BD is not a new process - with much work being carried out in the early part of the $20^{\text {th }}$ Century. However, with the advent of a cheap and seemingly plentiful supply of crude-oil this research fell out of favour. In the 1980s it became more popular and in the $21^{\text {st }}$ Century it is essential that we fully make use of this chemical technology. Thus, this short review will highlight the most recent examples of catalytic investigations into this process, the seminal initial work of Lebedev, Corson, Bhattacharyya and Ostromislenskiy has been the subject of review articles [8,9] and the reader is directed towards those and the primary literature for further details [10-21]. However, the scope of this review is to look at the most current literature in the area - the review focusses on sepiolite, $\mathrm{MgO}-\mathrm{SiO}_{2}$ and pure $\mathrm{SiO}_{2}$ supported catalysts.

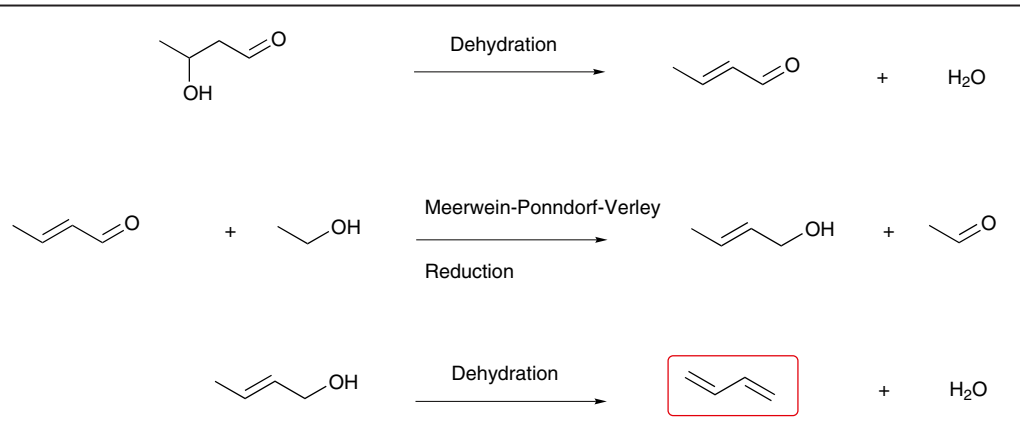

Scheme 2 Steps in involved in the conversion of ethanol to 1,3-BD. 
Post 1980's Catalytic conversion of Ethanol to 1,3-BD In 1981 Kitayama and co-workers investigated the catalytic activity of sepiolite $\left\{\left(\mathrm{H}_{2} \mathrm{O}\right)_{4}(\mathrm{OH})_{4} \mathrm{Mg}_{8} \mathrm{Si}_{12} \mathrm{O}_{30} \cdot 6-8 \mathrm{H}_{2} \mathrm{O}\right\}$ for the production of 1,3-BD [22]. Sepiolite was chosen as it is relatively easy to exchange the $\mathrm{Mg}$ (II) centres in the material with transition metals. In their study $\mathrm{Mn}$ (II) exchanged materials were investigated. The most promising results were observed at a temperature of $300^{\circ} \mathrm{C}$ with a $33.4 \%$ selectivity towards $1,3-\mathrm{BD}$, with $41.4 \%$ ethene. This is comparison to just 2.4\% 1,3-BD selectivity for the pure sepiolite material. The high quantity of ethene is a problem for this catalyst system and ethene should be avoided. Fripiat further investigated the substitution of sepiolite with either vanadyl or silver cations $[23,24]$. In the vanadyl case they observed only a modest selectivity to $1,3-\mathrm{BD}$ when pure ethanol was used as the feed [23]. However, when the feed was rich in acetaldehyde a high selectivity, ca. $80 \%$, to $1,3-$ $\mathrm{BD}$ was achieved. This was observed with and without the presence of the vandyl cation on the aluminated sepiolite. They proposed that the mechanism for this process involves the Prins reaction, Scheme 3:

For the silver aluminated sepiolite they observed that both the ethene and 1,3-BD selectivities increase linearly with total conversion [24]. They attributed this observation as support for the Prins mechanism. The Prins mechanism is an attractive approach as this can utilise the ethene by-product. However, since these initial studies the role of the Prins reaction has not been further investigated. The use of zeolites for this process is also not widely employed, this is presumably related to the high quantity of low-value ethene produced due to the acidic properties of most zeolites.

Magnesia-silica materials have been shown to be very effective catalysts (either pure supports or with added metal centres) for this process [25-27]. The magnesia offers basic sites and the silica acidic sites. It is hypothesised that the magnesia enhances the aldol and dehydrogenation steps of the mechanism, whereas the silica assists the dehydration steps on the mechanism. The preparation method and molar ratio of $\mathrm{MgO}$-to- $\mathrm{SiO}_{2}$ have proved to be of critical importance in this field. For example, Ohnishi prepared $\mathrm{MgO}: \mathrm{SiO}_{2}$ (with a 1:1 molar ratio) in three difference ways and observed yields of 1,3-BD ranging from $2-42 \%$ $\left(\mathrm{T}=350^{\circ} \mathrm{C}\right.$, Flow EtOH $\left.=6.5 \times 10^{-4} \mathrm{~mol} \mathrm{~h}^{-1}\right)$ [27]. It was observed that the most effective catalyst was prepared by the wet kneading of $\mathrm{Mg}(\mathrm{OH})_{2}$ \{prepared by hydrolysis of $\mathrm{Mg}\left(\mathrm{NO}_{3}\right)_{2}$ with $\mathrm{NH}_{3}$ \} with $\mathrm{SiO}_{2}$ \{prepared from hydrolysis of $\mathrm{Si}(\mathrm{OEt})_{4}$ with $\mathrm{HNO}_{3}, \mathrm{EtOH}$ and $\mathrm{NH}_{3}$. Using $\mathrm{MgCl}_{2}$ as the source of $\mathrm{MgO}$ resulted in significantly poorer yields of 1,3-BD. Interestingly, with the addition of $0.1 \mathrm{wt} \%$ of either $\mathrm{Na}_{2} \mathrm{O}$ or $\mathrm{K}_{2} \mathrm{O}$ then the selectivity to 1,3-BD significantly increases. This maybe due to the reduction in the Bronsted acidity of the support, highly Bronsted acidic materials are well known to catalyse the conversion of $\mathrm{EtOH}$ to ethene and diethyl ether. $\mathrm{MgO}: \mathrm{SiO}_{2}$ catalysts were also studied by Kvisle et al., the preparation of which was analogous to that of Ohnishi. Their catalytic tested were performed at $350^{\circ} \mathrm{C}$, flow $\mathrm{EtOH}=8 \mu \mathrm{l} \mathrm{h}^{-1}$, mass of catalyst $200 \mathrm{mg}$ [26]. They observed that as the flow of EtOH increases then the conversion decreases and the selectivity to 1,3-BD also decreases. The selectivity to $1,3-\mathrm{BD}$ could be increased by the addition of acetaldehyde to the feed or, interestingly, adding oxygen to the carrier gas. The addition of a second alcohol (methanol or isopropanol) did not alter the yield of 1,3-BD. It was thus hypothesised that the rate limiting step is not the hydrogen transfer step, which would be enhanced with the addition of other alcohols. Thus, the rate determining step occurs prior to the MPV step. It was also noted that the wet-kneaded catalyst significantly out performs (in terms of selectivity and longevity) a mechanical mixture of $\mathrm{MgO}$ and $\mathrm{SiO}_{2}$

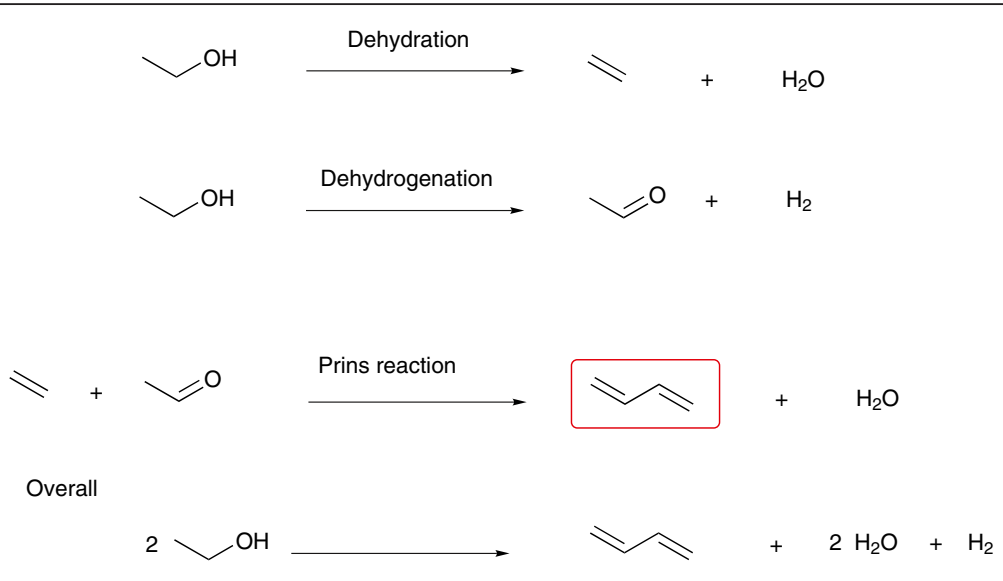

Scheme 3 Mechanism for the production of 1,3-BD from ethanol proposed by Fripiat. 
illustrating that there is a synergistic effect between the two oxides. Kitayama also prepared large surface area (up to $784 \mathrm{~m}^{2} \mathrm{~g}^{-1}$ ) nickel magnesium silicate materials for this process [28]. The catalysts were prepared with a $10 \mathrm{wt} \%$ $\mathrm{NiO}$ content, it was found that the optimum ratio of $\mathrm{Si} / \mathrm{Mg}$ was 1.5 , which afforded a $31 \%$ yield to $1,3-\mathrm{BD}$ and a very low selectivity to ethene of $0.5 \%$. It is believed that this ratio gives the optimum ratio of acid-tobase sites to enhance the selectivity to 1,3-BD. This was attributed to the decrease in the acid sites. Recently, Sels added transition metal centres to $\mathrm{MgO}: \mathrm{SiO}_{2}$ materials [25]. In their study the optimal ratio of $\mathrm{Mg} / \mathrm{Si}$ was 2 . Adding $\mathrm{CuO}, \mathrm{ZnO}$ and $\mathrm{Ag}$ to this support $\left(\mathrm{T}=350^{\circ} \mathrm{C}, \mathrm{EtOH}\right.$ concentration $=1.5 \times 10^{4} \mathrm{ppm}$ ) was seen to have a positive effect on selectivity. The preparation of these ternary systems was also investigated and it was found that the $\mathrm{MgO}$ : $\mathrm{SiO}_{2}$ must be prepared first followed by addition of the transition metal. Recently, Jones and co-workers have prepared a series of bimetallic $\left(\mathrm{ZnO} / \mathrm{ZrO}_{2}\right)$ supported $\mathrm{MgO}: \mathrm{SiO}_{2}$ catalysts [29]. For the undoped materials an optimum ratio of $\mathrm{Mg}: \mathrm{Si}$ was $2: 1\left(\mathrm{~T}=325^{\circ} \mathrm{C}\right.$, WHSV $=0.3$ $\mathrm{g}_{\mathrm{EtOH}} / \mathrm{g}_{\mathrm{cat}} \mathrm{h}$, mass of catalyst $\left.=1.0 \mathrm{~g}\right)$. However, this was not the case for the case for the bimetallic catalyst and the optimum ratio was 95:5 respectively. Interestingly, a small amount of $\mathrm{SiO}_{2}$ is essential for this process, with $100 \%$ $\mathrm{MgO}$ the conversion was $5 \%$ with a $19 \%$ selectivity to 1,3 BD compared to $30 \%$ and $68 \%$ for the $95: 5$ material. There are earlier examples of the exploitation of $\mathrm{MgO}-\mathrm{SiO}_{2}$ by Niiyama who showed that an 85:15 ratio was optimal for the process [25]. They observed that the rate determining step was acetaldehyde formation which was catalysed by the basic sites in the material. They argue that it is important to control the acidity and basicity of the catalyst. [30] Takezawa have also studied the mechanism for the conversion of ethanol to acetaldehyde on $\mathrm{MgO}$ supports, and the formation of an ethoxide species on the $\mathrm{MgO}$ was observed via IR spectroscopy [31].

Supports such as $\mathrm{SiO}_{2}$ and $\mathrm{Al}_{2} \mathrm{O}_{3}$ have also been utilised in the last three years for this process [32-35]. Jones has developed a series of bi- and tri-metallic catalysts for this reaction. They observed that with $\mathrm{EtOH}$ as the feed $\left(\mathrm{LHSV}=1.0 \mathrm{~h}^{-1}, \quad \mathrm{~T}=375^{\circ} \mathrm{C}\right)$ a $\mathrm{ZrO}_{2}: \mathrm{ZnO}: \mathrm{CuO}: \mathrm{SiO}_{2}$ (1 wt\% of each metal) catalyst was the most efficient giving a $67.4 \%$ selectivity to $1,3-\mathrm{BD}$ [34]. Interestingly, as the pore diameter $(40-60-150 \AA)$ of the porous $\mathrm{SiO}_{2}$ increased then the selectivity to $1,3-\mathrm{BD}$ increased. This was attributed to the acidity of the support decreasing, thus reducing the quantity of ethene formed. It was hypothesised that the $\mathrm{ZnO}$ was active for the dehydrogenation and the $\mathrm{ZrO}_{2}$ the aldol coupling step. Ordomskiy and co-workers have patented a series of gold, silver or copper and a metal oxide from magnesium, titanium, zirconium or tantalum deposited on $\mathrm{SiO}_{2}$ [35]. They achieved upto a $82 \%$ yield of $1,3-\mathrm{BD}\left(\mathrm{T}=325^{\circ} \mathrm{C}\right.$, WHSV $=$
$0.3 \mathrm{~g}_{\mathrm{EtOH}} / \mathrm{g}_{\text {cat }} \mathrm{h}, 1: 10$ acetaldehyde to ethanol) with a $\mathrm{Au}-\mathrm{ZrO}_{2}-\mathrm{SiO}_{2}$ material. They also observed high yields with $\mathrm{Ag}$ and $\mathrm{CeO}_{2}$ containing catalysts. Carbon (coking) formation is also possible for this process and will block access to active sites and thus reduce activity. This will require regeneration of the catalyst and periodic production downtime. Ezinkwo has shown that if $\mathrm{H}_{2} \mathrm{O}_{2}$ is added as a "process initiator" then this is a potential solution to coking issues [33]. Without the addition of the process initiator the catalyst was only lasted for 48 hours on stream. However, with the addition of $\mathrm{H}_{2} \mathrm{O}_{2}$ the catalyst activity persisted for 120 hours without reduction, indicating the possibility of running this catalysis in a continuous operation. The catalyst used in this study was a $\mathrm{ZnO} / \gamma-\mathrm{Al}_{2} \mathrm{O}_{3}$ system. In 2014, inspired by work in the early $20^{\text {th }}$ Century, Chae and co-workers produced $\mathrm{Ta}_{2} \mathrm{O}_{3}$ - supported on ordered mesoporous silica (SBA-15, MMS and KIT-6) [32]. They achieved conversions upto $47 \%$ and selectivity to $1,3-\mathrm{BD}$ of $80 \%\left(\mathrm{~T}=350^{\circ} \mathrm{C}\right.$, LHSV $\left.=1 \mathrm{~h}^{-1}\right)$. Importantly, it was observed that catalysts based on these ordered materials showed higher tolerances towards coke and higher activity.

\section{Conclusions}

The conversion of ethanol to 1,3-butadiene is becoming increasingly important in the $21^{\text {st }}$ Century. However, for the opportunities that this process offers to be fully realised the following problems still remain:

1) Increasing the selectivity, one of the most significant costs associated with the industrial scale-up of this process will be the separation of the 1,-BD from the by-products. Thus, the higher the selectivity then potentially the lower the cost of separation. The current literature clearly demonstrates that there needs to be the "goldilocks" condition of "just the right" balance of acid and base sites in the catalyst. It is anticipated that selectivities in excess of $70 \%$ will be required. This is a very challenging target given the plethora of possible side reactions.

2) The mechanism has been much debated in the literature. Future studies are required to fully ascertain the respective rates of the Prins mechanism compared to the aldol/hydrogen transfer process. These could entail isotopic labelling studies and/or computational analysis to fully probe which steps of the mechanism are occurring on which active site of the catalyst.

3) Reactor engineering, once the optimum catalyst has been developed studies are urgently required to develop reactors for this process - the relative merits of a fixed bed or fluidised bed reacts still needs to be investigated further [10]. Furthermore, 
work needs to be directed towards complications with coking [33].

\section{Competing interests}

The author declares that they have no competing interests.

\section{Acknowledgments}

MDJ wishes to thank the University of Bath, MDJ would also like to thank the collaborators of references 29 and 34.

Received: 21 May 2014 Accepted: 8 August 2014

Published online: 10 September 2014

\section{References}

1. White WC: Butadiene production process overview. Chem Biol Interact 2007, 166:10-14

2. Mascal M: Chemicals from biobutanol: technologies and markets. Biofuels Bioprod Biorefining 2012, 6:483-493.

3. Bruijnincx PCA, Weckhuysen BM: Shale gas revolution: an opportunity for the production of biobased chemicals? Angew Chem-Int Engl 2013, 52:11980-11987.

4. McMillan JD: Bioethanol production: Status and prospects. Renew Energ 1997, 10:295-302.

5. John RP, Anisha GS, Nampoothiri KM, Pandey A: Micro and macroalgal biomass: A renewable source for bioethanol. Bioresour Technol 2011, 102:186-193.

6. Patel AD, Meesters K, Den Uil H, De Jong E, Blok K, Patel MK: Sustainability assessment of novel chemical processes at early stage: application to biobased processes. Energy Environ Sci 2012, 5:8430-8444.

7. Patel AD, Meesters K, Den Uil H, De Jong E, Worrell E, Patel MK: Early-stage comparative sustainability assessment of new bio-based processes. ChemSusChem 2013, 6:1724-1736.

8. Angelici C, Weckhuysen BM, Bruijnincx PCA: Chemocatalytic conversion of ethanol into butadiene and other bulk chemicals. ChemSusChem 2013, 6:1595-1614.

9. Kozlowski JT, Davis RJ: Heterogeneous catalysts for the guerbet coupling of alcohols. ACS Catal 2013, 3:1588-1600.

10. Bhattacharyya SK, Avasthi BN: Catalytic conversion of ethanol to butadiene by two-step process in fluidised bed. J App/ Chem 1966, 16:239-244.

11. Bhattacharyya SK, Sanyal SK: Kinetic study on mechanism of catalytic conversion of ethanol to butadiene. J Catal 1967, 7:152-158.

12. Bhattacharyya SK, Avasthi BN: 1-step catalytic conversion of ethanol to butadiene in a fluidised bed. Ind Eng Chem Process Des Dev 1963, 2:45-51.

13. Corson BB, Jones HE, Welling CE, Hinckley JA, Stahly EE: Butadiene from ethyl alcohol - catalysis in the one-step and 2-step processes. Ind Eng Chem 1950, 42:359-373.

14. Corson BB, Stahly EE, Jones HE, Bishop HD: Butadiene from ethyl alcohol - study of the variables of operation. Ind Eng Chem 1949, 41:1012-1017.

15. Jones HE, Stahly EE, Corson BB: Butadiene from ethanol - reaction mechanism. J Am Chem Soc 1949, 71:1822-1828.

16. Quattlebaum WM, Toussaint WJ, Dunn J: Deoxygenation of certain aldehydes and ketones - preparation of butadiene and styrene. J Am Chem Soc 1947, 69:593-599.

17. Toussaint WJ, Dunn JT, Jackson DR: Production of butadiene from alcohol. Ind Eng Chem 1947, 39:120-125.

18. Murray IL, Marsh JL, Va W, Smith SP: US Patent. 1946. 2403742

19. Spence LU, Park E, Butterbaugh DJ, Kundiger DG: United States Pat; 1948. 2438464.

20. Lebedev SV, Gorin YA, Khutoretzkaya SN: The mechanism of the catalytic conversion of alcohols into biethylene hydrocarbons. Sint Kauch 1935, 4:8-27.

21. Lebedev SV: Preparation of bivinyl directly from alcohol. I. Zh Obshch Khim 1933, 3:698-717.

22. Kitayama Y, Michishita A: Catalytic activity of fibrous clay mineral sepilolite for butadiene formation from ethanol. J Chem Soc Chem Commun 1981, 401-402

23. Delacaillerie JBD, Gruver V, Fripiat JJ: Modification of the surface properties of natural phyllosilicate sepiolite by secondary isomorphic substitution. J Catal 1995, 151:420-430.

24. Gruver V, Sun A, Fripiat JJ: Catalytic properties of aluminated sepiolite in ethanol conversion. Catal Lett 1995, 34:359-364.
25. Makshina EV, Janssens W, Sels BF, Jacobs PA: Catalytic study of the conversion of ethanol into 1,3-butadiene. Catal Today 2012, 198:338-344.

26. Kvisle S, Aguero A, Sneeden RPA: Transformation of ethanol into 1,3-butadiene over magnesium-oxide silica catalysts. App/ Catal 1988, 43:117-131.

27. Ohnishi R, Akimoto T, Tanabe K: Pronounced Catalytic Activity and Selectivity of $\mathrm{MgO}-\mathrm{SiO}_{2}-\mathrm{Na}_{2} \mathrm{O}$ for Synthesis of Buta-1,3-diene from Ethanol. J Chem Soc Chem Commun 1985, 1613-1614.

28. Kitayama Y, Satoh M, Kodama T: Preparation of large surface area nickel magnesium silicate and its catalytic activity for conversion of ethanol into buta-1,3-diene. Catal Lett 1996, 36:95-97.

29. Lewandowski M, Babu GS, Vezzoli M, Jones MD, Owen RE, Mattia D, Plucinski P, Mikolajska E, Ochenduszko A, Apperley DC: Investigations into the conversion of ethanol to 1,3-butadiene using MgO:SiO2 supported catalysts. Catal Commun 2014, 49:25-28.

30. Niiyama H, Echigoya $E$, Morii S: Butadiene formation from ethanol over silica-magnesia catalysts. B Chem Soc Jpn 1972, 45:655-659.

31. Takezawa N, Hanamaki C, Kobayashi H: Mechamism of dehydrogenation of ethanol on magnesium-oxide. J Catal 1975, 38:101-109.

32. Chae H-J, Kim T-W, Moon Y-K, Kim H-K, Jeong K-E, Kim C-U, Jeong S-Y: Butadiene production from bioethanol and acetaldehyde over tantalum oxide-supported ordered mesoporous silica catalysts. App/ Catal B-Environ 2014, 150:596-604.

33. Ezinkwo GO, Tretjakov VF, Talyshinky RM, Ilolov AM, Mutombo TA: Creation of a continuous process for bio-ethanol to butadiene conversion via the use of a process initiator. Catal Commun 2014, 43:207-212.

34. Jones MD, Keir CG, Di lulio C, Robertson RAM, Williams CV, Apperley DC: Investigations into the conversion of ethanol into 1,3-butadiene. Catal Sci Technol 2011, 1:267-272.

35. Ordomskii W, Sushkevich VL, Ivanova II, Ordomskiy W, Ivanova LL: Patent WO2012015340-A1; 2012

doi:10.1186/s13065-014-0053-4

Cite this article as: Jones: Catalytic transformation of ethanol into 1,3-butadiene. Chemistry Central Journal 2014 8:53.

\section{Publish with ChemistryCentral and every scientist can read your work free of charge \\ "Open access provides opportunities to our colleagues in other parts of the globe, by allowing anyone to view the content free of charge." \\ W. Jeffery Hurst, The Hershey Company.}

- available free of charge to the entire scientific community

- peer reviewed and published immediately upon acceptance

- cited in PubMed and archived on PubMed Central

- yours - you keep the copyright

Submit your manuscript here:

http://www.chemistrycentral.com/manuscript/<smiles>c1ccccc1</smiles>

ChemistryCentral 